\title{
Construction and Implementation of Smart Home System
}

\author{
Augustine A. Habila \\ Department of Computer Science \\ Adawmawa State Universty, Mubi-Nigeria
}

\author{
Yusufu Gambo \\ Department of Computer Science \\ Adawmawa State Universty, Mubi-Nigeria
}

\begin{abstract}
Construction and implementation of an individual control home automation system using Raspberry pi micro controller and a GSM provide the automatic or semi-automatic control and monitoring of household appliances and residential house features like doors, gate and even the windows. This project is a demonstration of how to design and build a multipurpose remotely controlled system that can switch OFF and ON any electrical household appliance (including the security light), by dialing a phone already interfaced via relay module to a micro controller that controls a relay for the automatic switching on and off of the appliance and the phone will send a feedback short message service text indicating the new state of the appliance, whether switched ON or OFF. The results of this project show that a micro controller is a very powerful device for building smart electronic devices that can automatically control electrical appliances, with little circuitry complexities and components.
\end{abstract}

\section{General Terms}

Home automation system using raspberry pi

\section{Keywords}

Design, smart home, automation, microcontroller, raspberry, residential, appliances

\section{INTRODUCTION}

The increasing development in smart technologies such mobile technologies, internet of thing (IoT) devices, cloud computing etc., offer opportunities to controls devices around our environment. For example, switching on your air conditioning system ten minutes before you get home on a hot afternoon, security system that will detect smoke, excessive electrical power usage, burglar attempts and unauthorized movements in your house and alert you this kind of computing paradigm is known as home automation [4] Home automation is described as adding remote control to home appliances [2]. In fact, sophisticated home automation systems are now being developed that can maintain an inventory of household items, record their usage through an RFID (Radio Frequency Identification) tag, and prepare a shopping list or automatically order replacements. [4] stated that home automation has made it possible to have what is often referred to as a "smart home", a home that can detect and identify you, automatically adjust the lighting to your predefined taste, open doors automatically, play your favorite music, water your flowers in the morning, switch on the security lights at night and switch them off in the morning, heat water for bathe and tea, stream to you anywhere in the world via the internet a live video of what is happening in and around your house. It makes it possible to link lighting, entertainment, security, telecommunications, heating, and air conditioning into one centrally controlled system. This allows you to make your house an active partner in managing your busy life. Furthermore, [2] view that nowadays, you can hardly find a house without a home automation system which can range from the remote for the television, burglar alarm and hi-tech security gates, to an automated air conditioning system that maintains the temperature at a predefined value. The essences of automation to help build a smart home that unified all home appliance to detect and adapt to personalized for security alertness. A number of smart home project are being developed using smart technologies, nowadays IoTbased home automations are being developed and unified using smart application on smart mobile devices. The Internet of Things (IoT) is a rapidly growing network of variety of different "connected things". Use of IoT in home automation is like a new wave of change that has brought new opportunities and possibilities for the improvement of both home personalization and security. Furthermore, the concept of connected devices or things has given a new rise to the Internet, anything, anywhere can get connected with Internet and becomes 'Smart'. Connected devices can communicate with each other and share information which can then further be processed to take some decisions. The number of connected devices is increasing enormously and many predictions have been made with this regard. According to Gartner's prediction, 20.8 billion new things will be get connected by 2021 [5] The IoT based systems communicate through wireless technologies like RFID (Radio-Frequency Identification), ZigBee, NFC (Near Field Communication), WSN (Wireless Sensor Network), WLAN (Wireless Local Area Network), DSL (Digital Subscriber Line), UMTS (Universal Mobile Telecommunications System), WiMax (Worldwide Interoperability for Microwave Access), GPRS (General Packet Radio Service), or LTE (Long-Term Evolution) [6] The key challenges to IoT include security and privacy, availability, mobility, reliability, performance, interoperability, scalability, trust and management [1]. Most of the known challenges are stated in the surveys. As far as applications of IoT are concerned, there are various useful IoT applications based on the needs of potential users like Smart cities, Smart energy and Smart Grid, Smart Transportation and mobility, Smart homes, Smart building and infrastructure, Smart factory and manufacturing, Smart health, Food and water tracking and security [3] Several researches show that most of the recent studies propose different models for smart home using different technologies. These innovative devices simplify the process of communication among the devices and enhance security and personalization of the devices.

The paper proceeds as follows. Section 2 review related works, section 3 discuss system design while section 4 discussed system implementation. Conclusion is drawn in section 5 .

\section{RELATED WORKS}

The Phonebot responds to calls via, a ring detector circuit, which establishes a connection between the phone chip and 
the FPGA chip. [7] Smart phones/PDA (using touch screen user-friendly interface) has been deployed in recent robotic manipulation and control over the Internet, they fall short of balancing the complexities of the system against the usability of the system especially for the elderly/disabled.

[8]Apart from enhancing the convenience of smart home users, some research has been done in enhancing the human communication and control of home robotic systems. An earlier method of cell phone implementation was implemented by creating a communication link to control the 'Phonebot' over an analog phone system.

Several researches on constructing smart home system have been done. Developing a smart system based on Banana Pi which is cheap, small and flexible enough computer for daily life, and are accessible from Banana Pi on-board connectors and headers [9]. With the advantages that comes with a single-board computer; it can serve as a platform to make many applications for different purposes. Furthermore, [2] developed a system based on ZigBee technology as an end node, the node sends data to the coordinator, and the coordinator Hub sends the data back to the terminal end of the loop. Since all devices have their own IP Address based on IPv6, they can be directly connected to an external network. The overall system cost is very low as compare to other. The cost is dependent on advancement of system. The limitation of the Zigbee home automation is that If there any damage due to rupturing of cable the entire system gets crashed and. With an advantage of Zigbee home automation is, its low power consumption device and very less time-consuming system. Zigbee home automation make home safe and comfortable. Home automation takes less time to finish a task and also makes the work simpler. Moreover, [4] used Arduino microcontroller to implement home automation system. The Application developed using the Android platform controlled and monitored from a remote location using the smart home app and an Arduino Ethernet based micro web-server. The sensors and actuators/relays are directly interfaced to the main controller. The system offers the control of energy management systems such as lightings, heating, air conditioning, security, fire detection and intrusion detection with siren and email notifications. Some of the limitations of this technology are Adriano contains the web server application that communicates through the HTTP protocol with Web-based Android application.

\section{SYSTEM CONSTRUCTION}

The Input Devices: The basic requirement in a smart home system is the combination of certain hardware e.g. On control LED, OFF control LED and the Exit command

Processing: The GPIO controls relay configuration and the communication protocol between the hardware and software to send notification to the user.

Output Devices: such as the lamp status can either be turn on or turn off as output to the user based on the control of the user. The design and construction involved coupling several hardware components and testing at the different stages of the implementation.

i. Setting up the raspberry pi for the first time

ii. Connecting the pi with LCD display or laptop

iii. Loading and operating system unto the raspberry

iv. Configuring the pi to enable secure shell (SSH)

v. Accessing the device from a remote network vi. Configuring the General-purpose input and output pins (GPIO)

vii. Connecting raspberry pi with a relay board module

viii. Connecting home appliances with the relay module

ix. Testing

x. implementations and Results

Raspberry pi is connected with a display to load the Raspbian operating system on the raspberry.

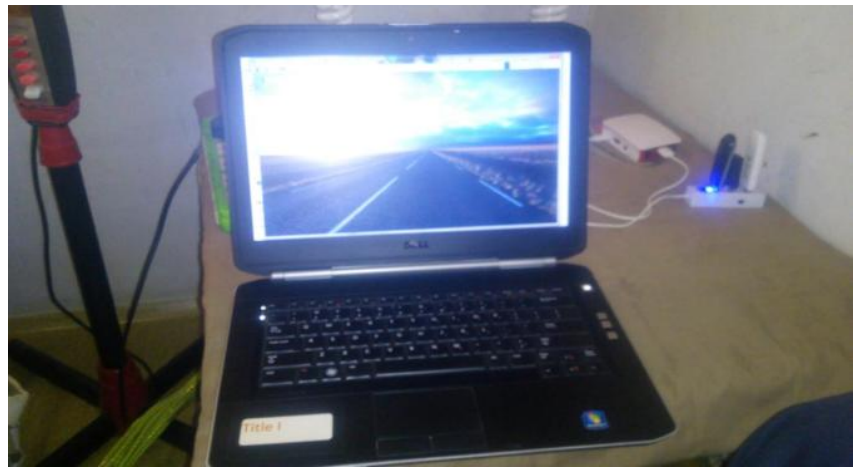

Fig. 1 Connected raspberry pi with a display

The connection of home appliances with the raspberry pi and the relay board module is shown in the Figure 2 below

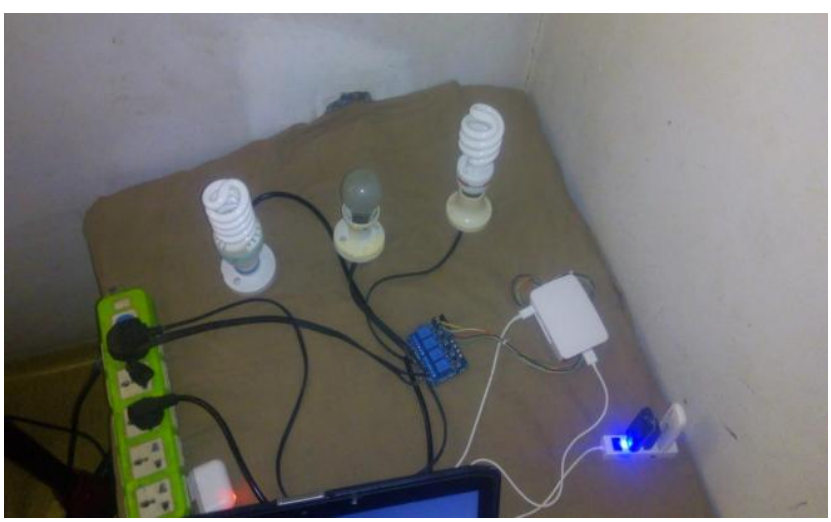

Fig. 2 Connected home appliances with raspberry pi

\section{SYSTEM IMPLEMENTATION}

Figure 3 and Figure 4 show how Raspberry Pi with Relay, Lamps and Fan devices are operated and executes the program which allows communications with the Smart phone and the computer system.

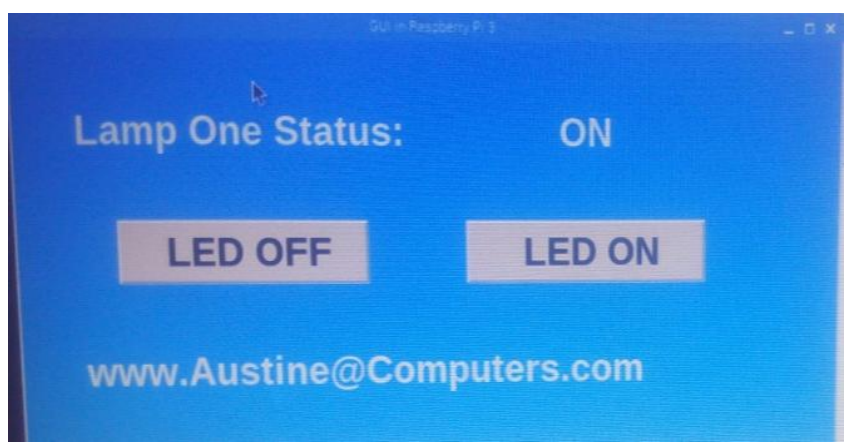

Fig. 3 Graphical user interface to control appliances

Fig.4 Shows the result output of the program at success 


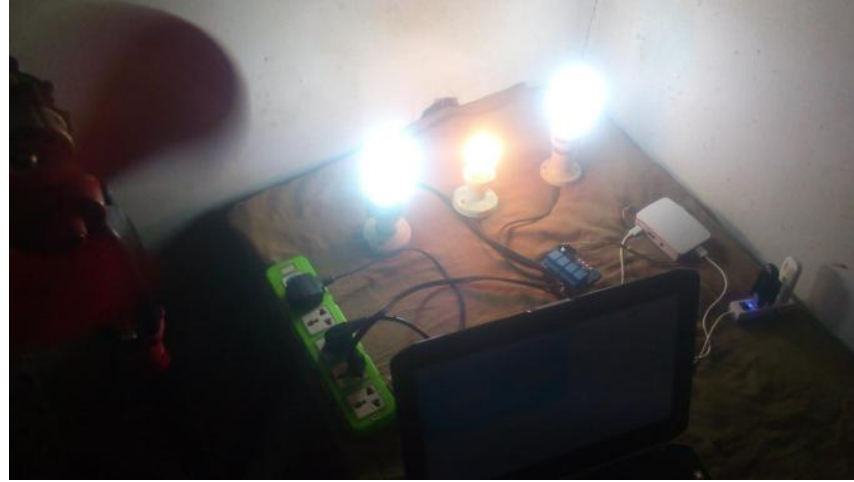

Fig. 4 Output results of the home appliances controlled

\section{CONCLUSION}

The construction of home automation system was tested a number of times and certified to control different home appliances used in the lighting system, air conditioning system, heating system, home entertainment system. This home automation system can also be implemented over Bluetooth, Infrared and WAP connectivity without much change to the design and yet still be able to control a variety of home appliances, hence this system is scalable and flexible.

\section{REFERENCES}

[1] Al-fuqaha, A, Guizani, M., Mohammadi, M. Aledhari, M., and Ayyash, M., (2015). "Internet of Things: A Survey on Enabling Technologies, Protocols and Applications
[2] Bhardwaj (2016). Interfacing PIC Microcontrollers Embedded Design by Interactive Simulation. Newnes, London, pp. 349-359,

[3] Chen, H., Xu, D. Liu, B. Hu, and H. Wang, (2014). "A vision of IoT: Applications, challenges, and opportunities with China Perspective," IEEE Internet Things J., 1(4), pp. 349-359, 2014.

[4] Greichen \& Vidhyalaks (2014). A project report on the design and construction of a low voltage power line communication system. Project Report, FUTA Akure. Intersil (2017). HIN232 datasheet. Intersil Inc, USA, pp. 221-212,

[5] Gul, G, Asi M., Ahmad S., Yasir M., Majid M., Malik S. (2017). A Survey on Role of Internet of Things in Education. International Journal of Computer Science and Network Security, 17(5)

[6] Marques, G., Garcia, N., and Pombo, N., (2017). "Advances in Mobile Cloud Computing and Big Data in the 5G Era," vol. 22, pp. 115-130, 2017.

[7] Schory, Guy. "Smart Homes, the Human Aspect." Home Toys. April 2018.

[8] R. Mihali, G. Gosine, P. Batra, A. Singh, S. Pathak, T. Vitulskis and A. Rosca, S. Grodzinsky, L. Hmurcik (2018).

[9] Zou \& Prashant (2017). An Introduction to programming the Microchip PIC in C. Character Press, UK. 